\title{
Establishing a Model Custom Hiring Center: A Feasibility Study at Kandi Mandal
}

\author{
B. Nagaraj*, Ch. Srilatha, S. Vikram, M. Venkatesh and Ch. Prameela \\ College of Agricultural Engineering, Sangareddy, Telangana-502001, India \\ *Corresponding author
}

\section{A B S T R A C T}

\begin{tabular}{|l|}
\hline K e y w o r d s \\
Machinery \\
economic feasibility \\
cropping pattern \\
soil type
\end{tabular}

\begin{abstract}
The present study was conducted in Kandi Mandal of Sangareddy district in Telangana state with objective of analyzing the cost of establishing a model custom hiring center in the study area with required machinery and its economic feasibility. The secondary data regarding the land holdings were collected from the Mandal Agricultural Office, Kandi and District Agricultural Office, Sangareddy. Secondary data about machinery and their prices were collected from Telangana State Agro Industries Development Corporation Limited (TSAIDCL), Hyderabad. Tabular analysis and discounted project evaluation techniques were used to worked out the establishment costs and returns and economic feasibility of the model CHC respectively. Based on the parameters like cropping pattern, soil type and land holdings the suitable type of implements and machinery were selected. The costs of the selected machinery and implements with and without subsidy were calculated and also the gross expenditure and gross income based on 100, 75 and 50 percent utilization of the services from the model CHC were also calculated. From the analysis it was found that the total cost of establishing a model CHC along with shed stood at Rs 70.4 and 37.45 lakhs without and with subsidy respectively. The gross income realized from the model CHC were Rs. 34.81, 26.11 and 17.41 lakhs and Rs.25.10,18.83 and 12.55 lakhs and the net income realized from the model CHC were Rs 13.81, 10.36, 6.90 lakhs and 7.37, 5.53 and 3.69 lakhs without and with subsidy at 100,75 and 50 percent utilization of services of machinery and implements respectively. The Net Present worth (NPW) was found positive and the Benefit Cost Ratio was more than unity at both 10 and 12 percent discount rates. The Internal Rate of Returns was found to be 14.76 percent and 14.83 percent without and with subsidy respectively which was higher than the bank rate of interest (7\%) on long term loans.
\end{abstract}

\section{Introduction}

Indian agriculture is undergoing a gradual shift from dependence on human power and draft animal power (DAP) to mechanical power. Mechanization of agricultural field operations is the need of hour in the present Indian Agriculture. Mechanization of agriculture in India has some constraints and limitations like high initial cost which often prohibits individual ownership especially amongst small, marginal and medium farm holders in addition to it, lack of knowledge in the aspects of operation, maintenance and repair of equipment often restricts the use of farm machinery and lack of space for shelter also constraints the use of machinery. To overcome the above problems and to achieve mechanization in the Indian farms custom hiring centers $(\mathrm{CHC})$ play a pivotal role in 
introducing high technology agricultural machinery even to small farmers with the objective to boost crop production, improve quality, timeliness and efficiency of agriculture operations. Mechanization of agriculture will help in increasing the productivity and reduce the cost of cultivation and also enable the farmer to complete farming operations in time.

The Custom Hiring Centers (CHCs) offer farm equipment's and machineries on rental basis to farmers who cannot afford to purchase high-end agricultural machineries and equipment's. Custom Hiring Centers (CHS) an important mechanism through which most small holders can access services of agricultural machinery.

The present study is an attempt to analyze the possibilities and prospects of increasing the farm income of small and medium farmers of the study area by establishing a model custom hiring center and also to evaluate the economic feasibility of the model CHC.

\section{Materials and Methods}

Kandi Mandal under Sangareddy District of Telangana state was chosen for the study. This area was chosen for the study as the farmers in this area are growing major crops like Paddy, Maize and Cotton where there is a scope for mechanization. Simple random sampling technique was adopted to select the ultimate sampling units of major crop growing farmers. Survey method was employed to collect the data from the farmers.

The study is based on primary data as well as secondary data. The primary data pertaining to the production aspects of major crops were collected directly from the farmers with the help of a specially designed schedule by personal interview and presented at current prices (2018-19) to estimate costs and returns.
The secondary data regarding the land holdings were collected from the Mandal Agricultural Office, Kandi and from the District Agricultural Office, Sangareddy and data about machinery and their prices were collected from Telangana State Agro Industries Development Corporation Limited (TSAIDCL), Hyderabad.

The computational procedure of cost of operation per hour of machinery is calculated by considering the two cost components of machinery i.e. fixed and variable costs. The variable costs such as labor, repairs, spare parts, fuel, lubrication and maintenance costs etc., increase proportionally with the operational use, while the fixed cost remains independent of the use of the respective machine or the implement. The annual fixed costs covered depreciation, interest on the investment and the insurance.

\section{Fixed costs}

\section{Depreciation}

Depreciation is the decrease in the value of a machine due to usage and time obsolescence. The decrease in value is on the account of the wearing out of the parts or on the reduced capacity of the machine with use.

Straight-line method is used to calculate depreciation considering the present and salvage value $(10 \%$ of $\mathrm{P})$ of the farm machines and implements.

Depreciation $=\frac{p-s}{L * H}, \mathrm{Rs} / \mathrm{h}$

Where, $\mathrm{D}=$ Depreciation, $\mathrm{Rs}$

$\mathrm{P}=$ Purchase price, $\mathrm{Rs}$

$\mathrm{S}=$ salvage Value, Rs

$\mathrm{L}=$ Economic machine life, years

$\mathrm{H}=$ Working hours per year 


\section{Interest}

Interest is used as a fixed cost estimate, as the money which has been once used to buy a machine cannot be used for any other productive purpose. In case of farm respondents, the cost of capital investment was accounted at 10 percent rate of interest.

$$
\mathrm{I}=\frac{\mathrm{p}+S}{2} X \frac{i}{H}
$$

Where,

$\mathrm{I}=$ Interest rate, $\mathrm{Rs}$

$\mathrm{i}=\%$ rate of the interest

$\mathrm{H}=$ working hours per year, $\mathrm{h}$

\section{Taxes, insurance and housing}

These three costs are usually much smaller than depreciation and interest, but they need to be considered. An estimated charge of 1.0 $\%$ of the purchase price is suggested for taxes, insurance and housing costs.

\section{Operating or variable cost}

\section{Fuel cost}

Fuel costs can be estimated by calculating the number of liters of fuel consumed in a year. In actual practice the fuel consumption is taken as 6 liters per hour for self-propelled machines.

\section{Lubrication cost}

Surveys indicate that total lubrication costs on most farms, on an average about $15 \%$ of fuel costs. Therefore, once the fuel cost per hour has been estimated, you can multiply it by 0.15 to estimate total lubrication costs.

\section{Repairs and maintenance}

Repairs and maintenance cost can be taken $10 \%$ of initial operating cost per year

\section{Labour}

The labour contributed by men, women and children of the farm operator or hired labour. The labour wages were allotted according to the work of operation of labour.

The data collected were subjected to conventional tabular analysis to work out costs and returns of model CHC. Discounted cash flow techniques were used to analyze the capital productivity of $\mathrm{CHC}$. The following discounted cash flow measures were used in the analysis viz., Net Present Worth, BenefitCost Ratio and Internal Rate of Returns.

\section{Net present worth (NPW):}

It is sometimes referred to as net present value. It is the present worth of the incremental net benefits or incremental cash flow stream. The selection criterion of the project depends on the positive value of the net present worth when discounted at the opportunity cost of the capital.

Net present worth $=\sum_{j=1}^{n} \frac{B j-C j}{(1+i)^{j}}$

Where,

$B_{j}=$ benefits in $j^{\text {th }}$ year

$\mathrm{C}_{\mathrm{j}}=$ costs in $\mathrm{j}^{\text {th }}$ year

$\mathrm{i}=$ discount rate

$\mathrm{n}=$ number of years

\section{Benefit-cost ratio (BCR)}

This ratio compares the present worth of costs with present worth of benefits. The common procedure of selecting the project is to choose the projects having the B.C. ratio of more than one, discounted at opportunity cost of capital.

Benefit cost ratio $=\frac{\sum_{j=1}^{\mathrm{n}} \frac{B_{j}}{(1+i)^{j}}}{\sum_{j=1}^{\mathrm{n}} \frac{C(j)}{(1+i)^{j}}}$ 
Where,

$B_{j}=$ benefits in $j^{\text {th }}$ year

$\mathrm{C}_{\mathrm{j}}=$ costs in $\mathrm{j}^{\text {th }}$ year

$\mathrm{i}=$ discount rate

$\mathrm{n}=$ number of years

\section{Internal rate of returns (IRR)}

It represents the average earning capacity of an investment over the economic life period of the project. It is that discount rate which just makes the net present worth of the cash flow equal to zero. In other words, the benefit cost ratio calculated at IRR is unity.

IRR is the maximum interest that a project could pay for the resources used if the project is to recover its investment and operating costs still break even. The IRR is arrived through interpolation technique by using different discount rates so as to see that the net present worth is equal to zero. Therefore, the project costs and benefits are discounted at a certain rate to find out the present worth of the project. Again, by selecting higher discount rate, the costs and returns are discounted throughout the project period to get a negative net present worth. The higher value of IRR indicates the first, while lowest value being the last choice of preference. However, the IRR should be more than the discount rate being considered for economic feasibility and financial soundness. If the calculated IRR is greater than the market rate of interest, then the investment is considered viable.

IRR

$=r a+N P V a(r b-r a) /(N P V a-N P V b)$

Where,

$r_{a}=$ lower discount rate

$\mathrm{r}_{\mathrm{b}}=$ higher discount rate

$\mathrm{NPV}_{\mathrm{a}}=\mathrm{NPV}$ using the lower discount rate $\mathrm{NPV}_{\mathrm{b}}=\mathrm{NPV}$ using the higher discount rate

\section{Results and Discussion}

\section{Category of land holdings in the study area}

The category of the land holdings in the study area are shown in the Table 1. The results showed that marginal and small farmers constituted about 91.8 percent, medium farmers accounted for 7.79 percent and large farmers constituted about 0.42 percent of the total land holdings in the study area.

\section{Cropping pattern in the study area}

The cropping pattern indicates the extent of area grown under each crop as a percentage of the total cropped area and is determined by the resource availability of the farm. It is evident from the Table 2 that, the principle crops grown in the study area (Kandi) are Maize, Cotton and Paddy which occupied $4242(32.28 \%), \quad 3686(28.05 \%) \quad$ and $1977(15.04 \%)$ acres respectively. Other principle crops grown in the study area are Jowar, Red gram, Soya bean etc.

\section{Cost of establishment of a model CHC}

Establishment of a $\mathrm{CHC}$ is a capital-intensive technology requiring a substantial investment especially during the initial establishment period. The model CHC to be established in the study area constitutes 19nosof machinery and implements considering the cropping pattern in the study area. Most of the farmers depends on expensive informal hiring systems, however timely availability is not assured and expressed their willingness to have a CHC. The total investment made on the different farm machinery and implements for establishing the model $\mathrm{CHC}$ is presented in Table 3. The total cost of establishing a model $\mathrm{CHC}$ along with shed is worked out as Rs 70.4 and 37.45 Lakhs without and with subsidy respectively. 


\section{Custom hiring charges}

The charges of custom hiring services of farm machinery were decided by calculating the cost of operation of each selected machinery and implement per hour by taking their fixed costs and variable costs. The custom hiring out charges per hour of farm machines and implements and average working hours per year of the model $\mathrm{CHC}$ are presented in Table

\section{Annual expenditure of model CHC}

The estimated annual expenditure under model $\mathrm{CHC}$ without subsidy as against with subsidy $(50 \%)$ to the farmers of study area providing custom hiring services of farm machinery and implements were given in Table 5\& Table 6. 4.

Table.1 Category of land holdings in the study area

\begin{tabular}{|c|l|c|c|}
\hline SI. No. & Category of farmers & No of farmers & Percentage (\%) \\
\hline $\mathbf{1}$ & Marginal & 8738 & 80.85 \\
\hline $\mathbf{2}$ & Small & 1183 & 10.95 \\
\hline $\mathbf{3}$ & Medium & 842 & 7.79 \\
\hline $\mathbf{4}$ & Large & 45 & 0.42 \\
\hline & TOTAL & $\mathbf{1 0 8 0 8}$ & $\mathbf{1 0 0}$ \\
\hline
\end{tabular}

Table.3 Cost of establishment of $\mathrm{CHC}$ with selected machinery without subsidy and with subsidy

\begin{tabular}{|c|l|c|c|c|c|}
\hline Sl.no. & Machinery and implements & $\begin{array}{c}\text { Quantity } \\
(\mathbf{n o})\end{array}$ & $\begin{array}{l}\text { Unit cost } \\
\text { Rs in lakhs) }\end{array}$ & \multicolumn{2}{|c|}{ Total cost } \\
\hline & & 1 & 7.5 & 7.5 & 3.75 \\
\hline $\mathbf{1}$ & Tractor & 1 & 1 & 1 & 0.5 \\
\hline $\mathbf{2}$ & Rotavator & 1 & 1.75 & 1.75 & 0.875 \\
\hline $\mathbf{3}$ & Tractor Trolley & 1 & 4 & 4 & 2 \\
\hline $\mathbf{4}$ & Laser Guided Land Leveler & 1 & 1 & 1 & 0.5 \\
\hline $\mathbf{5}$ & Reversible 2 MB Plough & 2 & 0.3 & 0.6 & 0.3 \\
\hline $\mathbf{6}$ & Cultivator (9 tine / 11 tine) & 1 & 0.4 & 0.4 & 0.2 \\
\hline $\mathbf{7}$ & Disc Plough & 2 & 0.15 & 0.3 & 0.15 \\
\hline $\mathbf{8}$ & Cage wheels & 1 & 0.6 & 0.6 & 0.3 \\
\hline $\mathbf{9}$ & Seed cum Fertilizer Drill & 1 & 1 & 1 & 0.5 \\
\hline $\mathbf{1 0}$ & Pneumatic Cotton Seed Planter & 1 & 14 & 14 & 7 \\
\hline $\mathbf{1 1}$ & Paddy transplanter(6or8 row) & 1 & 2 & 2 & 1 \\
\hline $\mathbf{1 2}$ & Automatic seedling machine & 1 & 0.8 & 0.8 & 0.4 \\
\hline $\mathbf{1 3}$ & Power Weeder & 2 & 0.02 & 0.04 & 0.02 \\
\hline $\mathbf{1 4}$ & Power sprayer & 5 & 0.2 & 1 & 0.5 \\
\hline $\mathbf{1 5}$ & Cotton picker & 1 & 25 & 25 & 12.5 \\
\hline $\mathbf{1 6}$ & combine harvester & 1 & 0.16 & 0.16 & 0.08 \\
\hline $\mathbf{1 7}$ & Maize Sheller & 1 & 3 & 3 & 1.5 \\
\hline $\mathbf{1 8}$ & Straw Baler & 1 & 1.75 & 1.75 & 0.875 \\
\hline $\mathbf{1 9}$ & Shredder & & & 4.5 & 4.5 \\
\hline $\mathbf{2 0}$ & Shed for implements 1000 sq. ft & & TOTAL & $\mathbf{7 0 . 4}$ & $\mathbf{3 7 . 4 5}$ \\
\hline
\end{tabular}


Table.4 Custom hiring out charges per hour of the selected farm machinery and implements in $\mathrm{CHC}(\mathrm{Rs})$

\begin{tabular}{|c|c|c|c|c|}
\hline \multirow[t]{2}{*}{ Sl.no. } & \multirow[t]{2}{*}{ Name of the Machinery } & \multicolumn{2}{|c|}{ Cost of operation per hour } & \multirow{2}{*}{$\begin{array}{c}\text { Working } \\
\text { hours /year }\end{array}$} \\
\hline & & o \% Subsidy & $50 \%$ Subsidy & \\
\hline 1 & Tractor & 865 & 762 & 1000 \\
\hline 2 & Rotavator & 93 & 47 & 300 \\
\hline 3 & Tractor Trolley & 140 & 70 & 300 \\
\hline 4 & Laser Guided Land Leveler & 185 & 93 & 550 \\
\hline 5 & Reversible 2 MB Plough & 93 & 47 & 300 \\
\hline 6 & Cultivator (9 tine / 11 tine) & 19 & 10 & 400 \\
\hline 7 & Disc Plough & 34 & 17 & 300 \\
\hline 8 & Cage wheels & 28 & 14 & 300 \\
\hline 9 & Seed cum Fertilizer Drill & 67 & 34 & 250 \\
\hline 10 & Pneumatic Cotton Seed Planter & 111 & 56 & 250 \\
\hline 11 & Paddy Trans planter ( 6 or 8 row) & 2388 & 1474 & 250 \\
\hline 12 & Automatic seedling machine & 315 & 158 & 200 \\
\hline 13 & Power Weeder & 529 & 493 & 300 \\
\hline 14 & Power sprayer & 255 & 254 & 250 \\
\hline 15 & Cotton picker & 70 & 11 & 250 \\
\hline 16 & Combine harvester & 2258 & 1459 & 500 \\
\hline 17 & Maize Sheller & 10 & 6 & 400 \\
\hline 18 & Straw Baler & 951 & 805 & 300 \\
\hline 19 & Shredder & 121 & 61 & 400 \\
\hline
\end{tabular}

Table.5 Gross expenditure, Gross income and net income per annum of model CHC without subsidy (in Rs. lakhs)

\begin{tabular}{|c|l|c|c|c|}
\hline \multirow{2}{*}{ Sl no } & Particulars & \multicolumn{3}{|c|}{ Utilization } \\
\cline { 3 - 5 } & & $\mathbf{1 0 0 \%}$ & $\mathbf{7 5 \%}$ & $\mathbf{5 0 \%}$ \\
\hline $\mathbf{1}$ & Gross Expenditure & 21.0 & 15.75 & 10.50 \\
\hline $\mathbf{2}$ & Gross Income & 34.81 & 26.11 & 17.41 \\
\hline $\mathbf{3}$ & Net income & 13.81 & 10.36 & 6.9 \\
\hline
\end{tabular}


Table.6 Gross expenditure, Gross income and net income per annum of model with subsidy (in Rs.lakhs)

\begin{tabular}{|c|l|c|c|c|}
\hline SI no & \multicolumn{1}{|c|}{ Particulars } & \multicolumn{3}{|c|}{ Utilization } \\
\cline { 3 - 5 } & & $\mathbf{1 0 0 \%}$ & $\mathbf{7 5 \%}$ & $\mathbf{5 0 \%}$ \\
\hline $\mathbf{1}$ & Gross Expenditure & 17.73 & 13.30 & 8.86 \\
\hline $\mathbf{2}$ & Gross Income & 25.10 & 18.83 & 12.55 \\
\hline $\mathbf{3}$ & Net income & 7.37 & 5.53 & 3.69 \\
\hline
\end{tabular}

Table.7 Estimation of NPW, BCR and IRR at various discount rates with $0 \%$ subsidy

\begin{tabular}{|c|l|c|c|c|}
\hline SI no & \multicolumn{1}{|c|}{ Particulars } & \multicolumn{3}{|c|}{ Discount rates } \\
\cline { 3 - 5 } & & $\mathbf{1 0 \%}$ & $\mathbf{1 2 \%}$ & $\mathbf{1 5 \%}$ \\
\hline $\mathbf{1}$ & Net present worth (Rs.) & 1172046.19 & 624999 & -52748.4 \\
\hline $\mathbf{2}$ & Benefit Cost Ratio & 1.0654 & 1.0372 & 0.9965 \\
\hline $\mathbf{3}$ & IRR & & $14.76 \%$ & \\
\hline
\end{tabular}

Table.8 Estimation of NPW, BCR and IRR at various discount rates with $50 \%$ subsidy

\begin{tabular}{|c|l|r|r|r|}
\hline SI no & \multicolumn{1}{|c|}{ Particulars } & \multicolumn{3}{|c|}{ Discount rates } \\
\cline { 3 - 5 } & & $\mathbf{1 0 \%}$ & $\mathbf{1 2 \%}$ & $\mathbf{1 5 \%}$ \\
\hline $\mathbf{1}$ & Net present worth (Rs.) & 632972 & 341135.45 & -20454.056 \\
\hline $\mathbf{2}$ & Benefit Cost Ratio & 1.0482 & 1.027 & 0.998 \\
\hline $\mathbf{3}$ & IRR & & $14.83 \%$ & \\
\hline
\end{tabular}

Economic viability of model custom hiring centre

The costs and returns are not the perfect measure to assess the profitability from investment made on $\mathrm{CHC}$. Before making a choice on any enterprise, it becomes necessary to examine the economic feasibility of that enterprise. The length of the period a particular enterprise bears fruits play a key role in the selection of indicators that would examine the economic feasibility of the enterprise. Several techniques are available for evaluating economic viability of $\mathrm{CHC}$. The cash inflows and outflows were discounted at 10, 12 and 15 per cent to estimate NPW, BCR and IRR with subsidy (50\%) and without subsidy.

It was observed from Tables 7 and 8 that the Net Present Worth was high and ranged from Rs $11,72,046.19$ at 10 percent to Rs 52,748.4 at 15 percent discount rates without subsidy and ranged from Rs 6,32,972 at 10 percent to 
Rs.20,454.056 at 15 percent discount rates with subsidy (50\%). The positive net Present Worth found between 10 and 12 percent discount rates indicated the soundness of the investment made in $\mathrm{CHC}$. The Benefit Cost Ratios worked out were 1.0654, 1.0372, and 0.9965 without subsidy and 1.0482, 1.027, and 0.998 with subsidy (50\%) at 10, 12 and 15 percent discount rates respectively. The Internal Rate of Returns was found to be more than the bank discount rate of $(7 \%)$ on long term loans and worked out as 14.76 percent and 14.83 percent without and with subsidy respectively. Hence the $\mathrm{CHC}$ enterprise is economically feasible.

The present study revealed that marginal and small farmers constitute about 90 percent of the land holdings. Hence, establishment of custom hiring centres at Mandal provides an opportunity to the marginal and small-scale farmers to avail the services of the expensive machines on custom hiring basis. The major crops like maize, paddy and cotton occupied $75 \%$ of the cropped area which are the major sources of income to the farmers and these crops are labour intensive too. Hence, establishment of $\mathrm{CHC}$ in the study area overcomes labour scarcity and nonavailability of machinery.

The total cost of establishing a model $\mathrm{CHC}$ in the study area stood at Rs 70.4 and 37.45 lakhs without and with subsidy. Subsidy scheme formulated by government will encourage young entrepreneurs and Agriengineering graduates to set up a $\mathrm{CHC}$ with low cost. The scope of establishing model $\mathrm{CHC}$ was encouraging as revealed through the net income generated by the model $\mathrm{CHC}$ with 100, 75 and 50 percent utilization of services of machinery and implements. The investment on model CHC was economically feasible as the NPW was positive at 10 and 12 percent interest rates and the BCR was more than one at the above interest rates.
The IRR was found to be more than bank rate of interest $(7 \%)$ under both cases of with and without subsidy.

\section{References}

Beaton A J, Dhuyvetter K C, and Kastens T L (2003) Custom rates and the total cost to own and operate farm machinery in Kansas. Available at http:// www.ksre.ksu.edu.

Parashunath, Hiremath G M and Prashanth.J (2016) constraints of farmers in utilizing custom hiring service (CHS) of tractor based farm machineries- An Analysis International Journal of Agricultural Science and Research.6(1):217-220.

Sharma V K, Singh K and Panesar B S (2005) customhiring of agricultural machinery and its future scope. Status Report on Farm Mechanization in India. pp 127132. Department of Agriculture and Cooperation, Ministry of Agriculture, Government of India, New Delhi.

Sidhu R S and Vatta K (2012) Improving economic viability of farming: A study of cooperative agro machinery service centres in Punjab. Agril Econ Res Rev25: 427434.

Srivastva N S L (1999) Role of agricultural engineering in doubling food production in next ten years. Agril Engg Today 23 (1-2): 37-49.

Thakur T C, Khura T K, Kishor R and Amdekar S J (2004) Economics of custom hiring of combine harvesters in north-western indo-gangetic plains of India- a case study. J Agril Engg 41 (4):16-24.

Vaja K.G, Dobariya U.D and Yadav Rajuir. (2016) Exploration of custom hiring services of farm machines in Junagadh International Journal of Agriculture Sciences. 8(47), 1946-1948. 


\section{How to cite this article:}

Nagaraj. B, Ch. Srilatha, S. Vikram, M. Venkatesh and Ch. Prameela. 2020. Establishing a Model Custom Hiring Center: A Feasibility Study at Kandi Mandal. Int.J.Curr.Microbiol.App.Sci. 9(05): 1299-1307. doi: https://doi.org/10.20546/ijcmas.2020.905.144 